\title{
Efficacy of totally laparoscopic distal gastrectomy for gastric cancer in elderly patients
}

\author{
KEITA KOUZU, HIRONORI TSUJIMOTO, SHUICHI HIRAKI, HIROYUKI HORIGUCHI, \\ SHINSUKE NOMURA, NOZOMI ITO, KYOHEI KANEMATSU, KENJI YAMAZAKI, \\ SUEFUMI AOSASA, JUNJI YAMAMOTO and KAZUO HASE
}

Department of Surgery, National Defense Medical College, Tokorozawa, Saitama 359-8513, Japan

Received May 6, 2015; Accepted December 11, 2015

DOI: $10.3892 / \mathrm{mco} .2016 .843$

\begin{abstract}
Elderly patients are often considered as high-risk for major abdominal surgery due to reduced functional reserve and increased comorbidities. We herein evaluated the efficacy of totally laparoscopic distal gastrectomy (TLDG) in elderly patients with gastric cancer by measuring the postoperative systemic responses and postoperative analgesic consumption. A total of 102 patients with gastric cancer [57 who underwent TLDG and 45 who underwent laparoscopy-assisted distal gastrectomy (LADG)] were enrolled in this study. The patients were classified as elderly (aged $\geq 75$ years) and non-elderly (aged $<75$ years) groups. The surgical outcome and postoperative analgesic consumption were evaluated. The elderly group exhibited a higher incidence of comorbidities and a longer postoperative hospital stay compared with those of younger patients, although there was no difference in the incidence of postoperative complications. In addition, the total consumption of additional analgesics until postoperative day 5 in patients who underwent TLDG was significantly lower compared with that in patients who underwent LADG in the elderly group; there was no such difference in the non-elderly group. The results suggested that TLDG was better for the management of postoperative pain in elderly patients with gastric cancer, who exhibit the highest mortality rates in the adult surgical population.
\end{abstract}

\section{Introduction}

The aging trend in Japan and Korea has been significant, with $>30 \%$ of gastric cancer patients in these countries being aged $>70$ years $(1,2)$. Elderly patients are often considered as high-risk for major abdominal surgery due to reduced functional reserve and increased comorbidities (3).

Correspondence to: Dr Hironori Tsujimoto, Department of Surgery, National Defense Medical College, 3-2 Namiki, Tokorozawa, Saitama 359-8513, Japan

E-mail: tsujihi@ndmc.ac.jp

Key words: laparoscopy-assisted distal gastrectomy, early outcome, cosmetic outcome, gastric cancer, elderly patients
Since the first published report of laparoscopy-assisted distal gastrectomy (LADG) for early gastric cancer in 1994 (4), the number of patients who have undergone LADG in Japan has significantly increased; according to a Japanese nationwide survey of endoscopic surgery, $>9,000$ cases of LADG were performed in 2013 (5). It has been reported that LADG for early gastric cancer has long-term oncological outcomes equivalent to those of conventional open distal gastrectomy (CODG) (6). In addition, several meta-analyses have demonstrated short-term advantages for LADG over CODG in terms of intraoperative blood loss, postoperative analgesic consumption and length of hospital stay, as well as a better cosmetic outcome (7-9). Recent advances in laparoscopic techniques have facilitated the development of several intracorporeal anastomosis methods, which enabled totally laparoscopic gastrectomy to be performed without additional incisions for anastomosis (10-14).

In this study, we evaluated the efficacy of totally laparoscopic distal gastrectomy (TLDG) in elderly patients with gastric cancer through measuring postoperative systemic responses and postoperative analgesic consumption.

\section{Patients and methods}

Patients. A total of 102 consecutive patients with gastric cancer underwent laparoscopic distal gastrectomy at the Department of Surgery, National Defense Medical College Hospital (Tokorozawa, Japan) between 2010 and 2014. Prior to August, 2012, LADG was performed in 45 patients; after that time, TLDG was performed in 57 patients among all eligible cases. The patients were classified into elderly (aged $\geq 75$ years) and non-elderly (aged $<75$ years) groups. The clinicopathological characteristics of the patients were evaluated on the basis of the Japanese Classification of Gastric Carcinoma (3rd English edition) published by the Japanese Gastric Cancer Association (15). There was no change in the delivery of postoperative care during this period. The medical and nursing charts of the patients were retrospectively evaluated for preoperative status, type of surgical procedure, analgesic consumption and postoperative systemic response, including white blood cell (WBC) count, body temperature, heart rate, levels of C-reactive protein (CRP) and all laboratory data up to postoperative day (POD) 7 . 

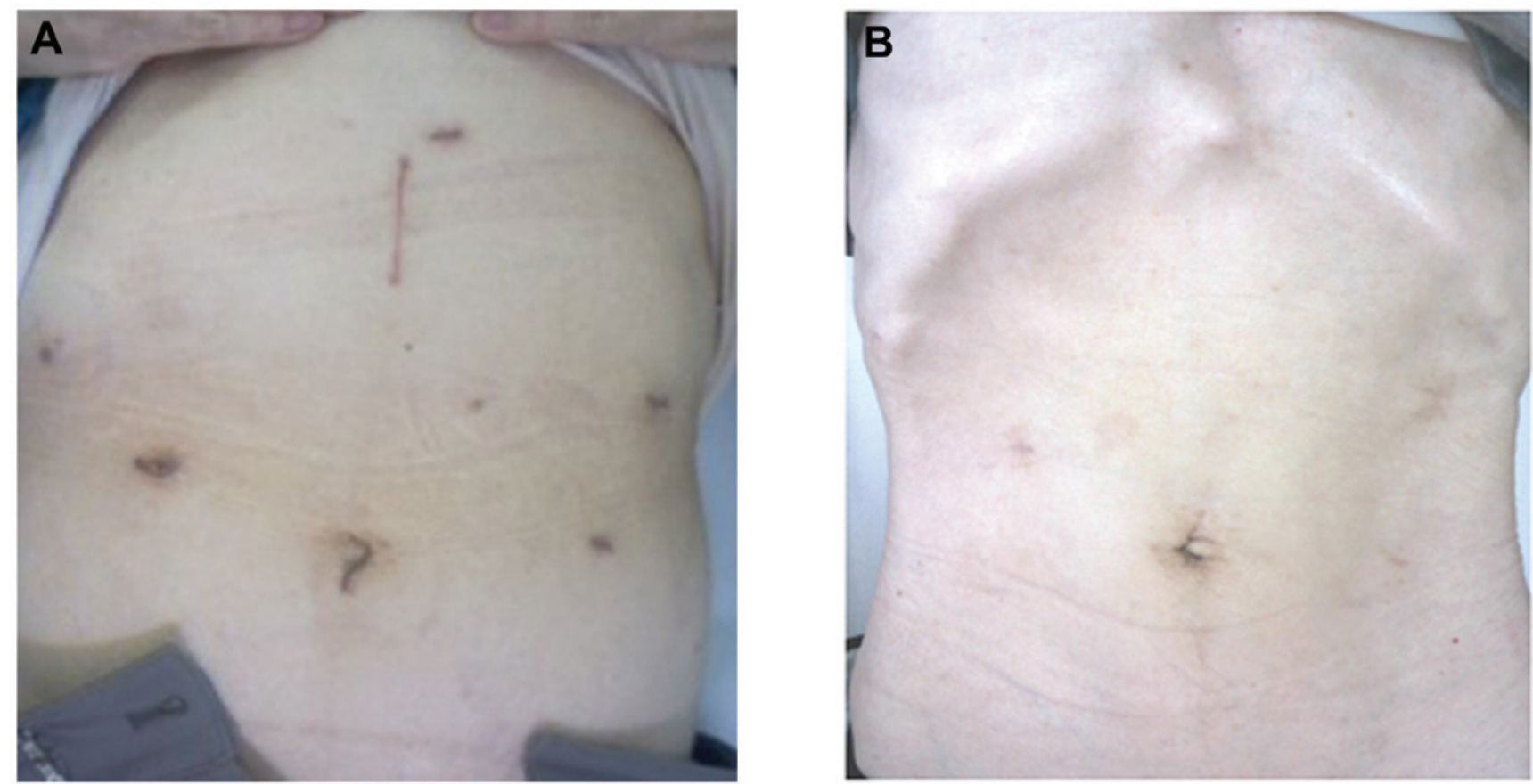

Figure 1. Postoperative view of the surgical wounds 6 months after gastrectomy. (A) Laparoscopy-assisted distal gastrectomy. (B) Totally laparoscopic distal gastrectomy.

This was a non-randomized study and informed consent was obtained from all the participants prior to study initiation.

Operative procedures. Following induction of general anesthesia with an epidural catheter, each patient was placed in the supine position. The surgeon was positioned on the left side of the patient, the first assistant was on the right, and the laparoscopist was located between the abducted legs of the patient. A camera port was inserted into a median umbilical incision. Following this, a pneumoperitoneum of $12 \mathrm{mmHg}$ was created and 4 additional ports ( 2 ports of $12 \mathrm{~mm}$ in diameter and 2 ports of $5 \mathrm{~mm}$ in diameter) were inserted under laparoscopic imaging into the left upper, right lower, left lower, and right upper quadrants. An ultrasonically-activated sealing device (Harmonic Scalpel Ace; Ethicon, Tokyo, Japan) and a vessel-sealing device (LigaSure V; Tyco Healthcare, Tokyo, Japan) were used in the dissecting procedures.

For the LADG cases, following gastrectomy with lymphadenectomy, depending on the tumor stage, a median superior abdominal incision $\sim 4 \mathrm{~cm}$ in length was created (Fig. 1A). A Billroth I reconstruction was then usually performed by the hemi-double stapling technique using a $25-\mathrm{mm}$ circular stapler (Covidien, Tokyo, Japan), as previously described (16). The stomach was transected with a linear stapler and the specimen was collected through a mini-laparotomy. When the extracorporeal Billroth I reconstruction was expected to be strained, a Roux-en-Y reconstruction was selected and anastomoses were performed through mini-laparotomy.

For cases with TLDG, following gastrectomy, the umbilical trocar incision was extended to $\sim 2 \mathrm{~cm}$ by enlarging the median fascia and skin incisions; tumors and surrounding tissues were pulled out through the umbilical incision (Fig. 1B). Intracorporeal Billroth I anastomosis was performed using the $\delta$-shaped anastomosis, as previously described (13). When a Roux-en-Y reconstruction was employed, all anastomoses were performed using laparoscopic linear staplers and/or a hand-suturing technique.

Postoperative analgesia. Postoperative pain was controlled by epidural anesthesia, and patients were allowed to have additional analgesia when necessary. The surgeon in charge determined the time of epidural catheter removal, while managing the patient's pain. Oral or intravenous non-steroidal anti-inflammatory drugs or intravenous pentazocine hydrochloride were employed as rescue medications.

Statistical analysis. The statistical analyses were performed using the JMP 10.0.0 software package (SAS Institute, Cary, $\mathrm{NC}, \mathrm{USA}$ ). The data are expressed as the mean \pm standard error. Statistical analyses were performed using the Student's t-test or Chi-square test with the Fisher's exact test, whichever was considered appropriate. $\mathrm{P}<0.05$ was considered to indicate a statistically significant difference.

\section{Results}

Demographic data and surgical outcomes of the elderly and non-elderly groups. The elderly and non-elderly groups were matched for age, gender, location and size of tumor, histological differentiation, pathological tumor depth, nodal involvement and stage, except for body mass index (BMI) (Table I). In addition, there were no differences in age, gender, location and size of tumor, histological differentiation, nodal involvement, BMI or tumor stage among the patients who underwent TLDG and those who underwent LADG for both groups (data not shown). When compared with the non-elderly group, the elderly group exhibited a higher frequency of comorbidities, such as cardiovascular and respiratory diseases (Table I). There was 
Table I. Demographic data of the elderly and non-elderly groups.

\begin{tabular}{|c|c|c|c|}
\hline Characteristics & $\begin{array}{l}\text { Non-elderly group } \\
\qquad(\mathrm{n}=77)\end{array}$ & $\begin{array}{l}\text { Elderly group } \\
\quad(\mathrm{n}=25)\end{array}$ & P-value \\
\hline \multicolumn{4}{|l|}{ Gender, n (\%) } \\
\hline Male & $56(72.7)$ & $20(80.0)$ & \multirow[t]{2}{*}{0.469} \\
\hline Female & $21(27.3)$ & $5(20.0)$ & \\
\hline Body mass index $\left(\mathrm{kg} / \mathrm{m}^{2}\right)$ & $22.3 \pm 3.1$ & $20.4 \pm 2.1$ & 0.003 \\
\hline \multicolumn{4}{|l|}{ Tumor location, n (\%) } \\
\hline Middle third & $22(28.6)$ & $8(32.0)$ & \multirow[t]{2}{*}{0.772} \\
\hline Lower third & $55(71.4)$ & $17(68.0)$ & \\
\hline Maximal tumor size (mm) & $38.5 \pm 23.2$ & $35.3 \pm 16.6$ & 0.523 \\
\hline \multicolumn{4}{|c|}{ Histological classification, n (\%) } \\
\hline Intestinal & $44(57.1)$ & $14(56.0)$ & \multirow[t]{2}{*}{0.920} \\
\hline Diffuse & $33(42.9)$ & $11(44.0)$ & \\
\hline \multicolumn{4}{|l|}{ Tumor depth } \\
\hline pT1 & 49 (63.6) & $21(84.0)$ & \multirow[t]{2}{*}{0.057} \\
\hline pT2-T4 & $28(36.4)$ & $4(16.0)$ & \\
\hline \multicolumn{4}{|c|}{ Lymph node metastasis, n (\%) } \\
\hline pNO & $60(77.9)$ & $20(80.0)$ & \multirow[t]{2}{*}{0.826} \\
\hline pN1-3 & $17(22.1)$ & $5(20.0)$ & \\
\hline \multicolumn{4}{|l|}{ pStage, n (\%) } \\
\hline I & 59 (76.6) & $21(84.0)$ & \multirow[t]{3}{*}{0.474} \\
\hline II & $12(15.6)$ & $2(8.0)$ & \\
\hline III & $6(7.8)$ & $1(4.0)$ & \\
\hline \multicolumn{4}{|l|}{ Comorbidity, n (\%) } \\
\hline Yes & $32(41.6)$ & $21(84.0)$ & \multirow[t]{2}{*}{$<0.001$} \\
\hline No & $45(58.4)$ & $4(16.0)$ & \\
\hline \multicolumn{4}{|c|}{ Number of comorbidities, (\%) } \\
\hline 0 & $45(58.4)$ & $4(16.0)$ & \multirow[t]{3}{*}{$<0.001$} \\
\hline 1 & $23(29.9)$ & $12(48.0)$ & \\
\hline 2 & $9(11.7)$ & $9(36.0)$ & \\
\hline \multicolumn{4}{|l|}{ Comorbid diseases, n (\%) } \\
\hline Cardiovascular & $24(31.2)$ & $15(60.0)$ & 0.010 \\
\hline Respiratory & $3(3.9)$ & $4(16.0)$ & 0.038 \\
\hline Liver & $1(1.3)$ & $0(0.0)$ & 0.567 \\
\hline Renal & $1(1.3)$ & $1(4.0)$ & 0.397 \\
\hline Diabetes mellitus & $6(7.8)$ & $5(20.0)$ & 0.087 \\
\hline Collagen disease & $3(3.9)$ & $0(0.0)$ & 0.317 \\
\hline Thyroid disease & $0(0.0)$ & $1(4.0)$ & 0.078 \\
\hline
\end{tabular}

no difference in operative outcome between the two groups, such as extent of lymphadenectomy, total number of harvested lymph nodes and type of reconstruction (Table II). Although there was no difference in the occurrence of postoperative complications, it required a significantly longer time for the elderly group to start oral intake and be discharged from the hospital; in addition, the elderly group had more intraoperative bleeding compared with the non-elderly group. There were no cases of conversion to open surgery in either group.

Postoperative systemic responses of the elderly andnon-elderly groups. There was no difference in the postoperative WBC,
CRP, body temperature or heart rate between the two groups (data not shown). In the non-elderly group, the WBC levels on POD3 and the CRP levels on POD1 and 3 in patients who underwent TLDG were significantly higher compared with those in patients who underwent LADG; these differences were not observed in the elderly group (Fig. 2).

Postoperative analgesic consumption. No difference was observed in the duration of epidural anesthesia between the two groups (Table III). The elderly group required less frequent additional analgesia postoperatively, albeit not significantly. We next compared the postoperative analgesia consumption according 
Table II. Surgical outcomes of the elderly and non-elderly groups.

\begin{tabular}{|c|c|c|c|}
\hline Variables & $\begin{array}{l}\text { Non-elderly group } \\
\qquad(\mathrm{n}=77)\end{array}$ & $\begin{array}{l}\text { Elderly group } \\
\qquad(\mathrm{n}=25)\end{array}$ & P-value \\
\hline \multicolumn{4}{|l|}{ Lymphadenectomy, n (\%) } \\
\hline $\mathrm{D} 1, \mathrm{D}^{+}$ & $39(50.6)$ & $18(72.0)$ & \multirow[t]{2}{*}{0.062} \\
\hline D2 & $38(49.4)$ & $7(28.0)$ & \\
\hline \multicolumn{4}{|l|}{ Surgery, n (\%) } \\
\hline LADG & $35(45.5)$ & $10(40.0)$ & \multirow[t]{2}{*}{0.633} \\
\hline TLDG & $42(54.5)$ & $15(60.0)$ & \\
\hline Total number of harvested LNs & $34.9 \pm 17.1$ & $34.6 \pm 19.3$ & 0.932 \\
\hline \multicolumn{4}{|l|}{ Reconstruction, n (\%) } \\
\hline Billroth I & $45(58.4)$ & $19(76.0)$ & \multirow[t]{2}{*}{0.115} \\
\hline Roux-en-Y & $32(41.6)$ & $6(24.0)$ & \\
\hline Time until start of oral intake (days) & $3.3 \pm 0.6$ & $4.6 \pm 3.7$ & 0.005 \\
\hline Hospital stay (days) & $9.8 \pm 13.2$ & $13.2 \pm 10.6$ & 0.022 \\
\hline Operative time $(\min )$ & $247.6 \pm 48.7$ & $243.5 \pm 60.5$ & 0.839 \\
\hline Intraoperative bleeding (ml) & $54.1 \pm 108.9$ & $109.8 \pm 151.7$ & 0.048 \\
\hline Conversion to open surgery, n (\%) & $0(0.0)$ & $0(0.0)$ & $>0.99$ \\
\hline \multicolumn{4}{|l|}{ Postoperative complications, n (\%) } \\
\hline Yes & $11(14.3)$ & $5(20.0)$ & \multirow[t]{2}{*}{0.495} \\
\hline No & $66(85.7)$ & $20(80.0)$ & \\
\hline Pneumonia & $2(2.6)$ & $0(0.0)$ & 0.416 \\
\hline Leakage & $2(2.6)$ & $3(12.0)$ & 0.059 \\
\hline SSI & $2(2.6)$ & $1(4.0)$ & 0.718 \\
\hline DGE & $2(2.6)$ & $0(0.0)$ & 0.416 \\
\hline Pancreatic fistula & $1(1.3)$ & $0(0.0)$ & 0.567 \\
\hline Bleeding & $1(1.3)$ & $0(0.0)$ & 0.567 \\
\hline Cholangitis & $0(0.0)$ & $1(4.0)$ & 0.078 \\
\hline UTI & $1(1.3)$ & $0(0.0)$ & 0.567 \\
\hline
\end{tabular}

LADG, laparoscopy-assisted distal gastrectomy; TLDG, totally laparoscopic distal gastrectomy; UTI, urinary tract infection; LN, lymph node; SSI, surgical site infection; DGE, delayed gastric emptying.

to surgical procedure between the two groups (Table IV). In both groups, the duration of epidural anesthesia in patients who underwent TLDG was shorter compared with that in patients who underwent LADG. The frequencies of additional analgesia use on POD1 and 2 in patients who underwent TLDG were lower compared with that in patients who underwent LADG in the elderly group, and the total consumption of additional analgesics until POD5 in patients who underwent TLDG was significantly lower compared with that in patients who underwent LADG in the elderly group; there was no such trend in the non-elderly group. In addition, as compared with the patients in the non-elderly group on POD1 and 2, the consumption and the need for additional analgesia for patients who underwent TLDG in the elderly group were significantly lower.

\section{Discussion}

As elderly individuals are currently representing a rapidly increasing percentage of the population, the mean age and number of patients with various malignancies have increased (1). The functional capacity of organs decreases with age, resulting in a decreased reserve and lower ability to endure stress (17); therefore, advanced age is a significant risk factor for increased mortality (18). However, advances in surgical and anesthesiology techniques have reportedly reduced surgical complications and have, consequently, improved the short-term surgical outcomes in elderly patients $(19,20)$.

In this study, there were no differences in postoperative systemic responses (WBC, CRP, body temperature and heart rate) between the TLDG and LADG procedures in the elderly group, and the total consumption of additional analgesics until POD5 in patients who underwent TLDG was significantly lower compared with that in patients who underwent LADG in the elderly group; the patients who underwent TLDG had a relatively shorter duration of epidural anesthesia. Our present data pose a question regarding the mechanism(s) of differential postoperative pain between elderly and non-elderly patients that may be explained as follows: i) It has been reported that aging-related anatomic changes may affect the spreading pattern of the local anesthetic injected into the epidural 
Table III. Postoperative analgesia consumption in the elderly and non-elderly groups.

\begin{tabular}{lccr}
\hline Variables & $\begin{array}{c}\text { Non-elderly group } \\
(\mathrm{n}=77)\end{array}$ & $\begin{array}{c}\text { Elderly group } \\
(\mathrm{n}=25)\end{array}$ & P-value \\
\hline $\begin{array}{l}\text { Duration of epidural anesthesia (days) } \\
\text { Frequency of additional analgesia use }\end{array}$ & $2.8 \pm 0.8$ & $2.8 \pm 0.8$ & 0.971 \\
POD1 & $0.51 \pm 0.75$ & $0.24 \pm 0.60$ & 0.111 \\
POD2 & $1.00 \pm 1.01$ & $0.64 \pm 0.86$ & 0.113 \\
POD3 & $0.82 \pm 0.90$ & $0.64 \pm 0.86$ & 0.387 \\
POD4 & $0.53 \pm 0.87$ & $0.28 \pm 0.61$ & 0.181 \\
POD5 & $0.26 \pm 0.55$ & $0.20 \pm 0.41$ & 0.617 \\
Total & $3.12 \pm 2.85$ & $2.00 \pm 2.57$ & 0.085 \\
Incidence of using additional analgesia, $\mathrm{n}(\%)$ & & & \\
POD1 & $15(35.7)$ & $1(6.7)$ & 0.106 \\
POD2 & $25(59.5)$ & $5(33.3)$ & 0.147 \\
POD3 & $22(52.4)$ & $4(26.7)$ & 0.072 \\
POD4 & $14(33.3)$ & $2(13.3)$ & 0.280 \\
POD5 & $9(21.4)$ & $2(13.3)$ & 0.280 \\
\hline
\end{tabular}

POD, postoperative day.

Table IV. Postoperative analgesia consumption according to the surgical procedure in the elderly and non-elderly groups.

\begin{tabular}{|c|c|c|c|c|c|c|}
\hline \multirow[b]{2}{*}{ Variables } & \multicolumn{2}{|c|}{ Non-elderly group } & \multirow[b]{2}{*}{ P-value } & \multicolumn{2}{|c|}{ Elderly group } & \multirow[b]{2}{*}{ P-value } \\
\hline & $\begin{array}{l}\text { TLDG } \\
(\mathrm{n}=42)\end{array}$ & $\begin{array}{l}\text { LADG } \\
(\mathrm{n}=35)\end{array}$ & & $\begin{array}{l}\text { TLDG } \\
(\mathrm{n}=15)\end{array}$ & $\begin{array}{l}\text { LADG } \\
(\mathrm{n}=10)\end{array}$ & \\
\hline Duration of epidural anesthesia (days) & $2.5 \pm 0.8$ & $2.8 \pm 0.7$ & 0.084 & $2.6 \pm 0.6$ & $3.1 \pm 0.8$ & 0.135 \\
\hline \multicolumn{7}{|l|}{ Frequency of additional analgesia use } \\
\hline POD1 & $0.45 \pm 0.67$ & $0.57 \pm 0.85$ & 0.656 & $0.07 \pm 0.26^{\mathrm{a}}$ & $0.50 \pm 0.84$ & 0.108 \\
\hline POD2 & $1.04 \pm 0.99$ & $0.94 \pm 1.06$ & 0.476 & $0.40 \pm 0.63^{\mathrm{a}}$ & $1.00 \pm 1.05$ & 0.122 \\
\hline POD3 & $0.83 \pm 0.88$ & $0.80 \pm 0.93$ & 0.800 & $0.40 \pm 0.74$ & $1.00 \pm 0.94$ & 0.087 \\
\hline POD4 & $0.50 \pm 0.80$ & $0.57 \pm 0.95$ & 0.879 & $0.20 \pm 0.56$ & $0.40 \pm 0.70$ & 0.340 \\
\hline POD5 & $0.26 \pm 0.54$ & $0.26 \pm 0.56$ & 0.902 & $0.13 \pm 0.35$ & $0.30 \pm 0.48$ & 0.317 \\
\hline Total & $3.10 \pm 2.64$ & $3.14 \pm 3.13$ & 0.840 & $1.20 \pm 2.11^{\mathrm{a}}$ & $3.20 \pm 2.82$ & 0.015 \\
\hline \multicolumn{7}{|c|}{ Incidence of additional analgesia use, $\mathrm{n}(\%)$} \\
\hline POD1 & $15(35.7)$ & $14(40.0)$ & 0.331 & $1(6.7)^{\mathrm{a}}$ & $3(30)$ & 0.106 \\
\hline POD2 & $25(59.5)$ & $22(62.9)$ & 0.494 & $5(33.3)$ & $6(60)$ & 0.147 \\
\hline POD3 & $22(52.4)$ & $18(51.4)$ & 0.534 & $4(26.7)$ & $6(60)$ & 0.072 \\
\hline POD4 & $14(33.3)$ & $12(34.3)$ & 0.927 & $2(13.3)$ & $3(30)$ & 0.280 \\
\hline POD5 & $9(21.4)$ & $7(20)$ & 0.614 & $2(13.3)$ & $3(30)$ & 0.280 \\
\hline
\end{tabular}

${ }^{\text {a }} \mathrm{P}<0.05$ for the elderly vs. non-elderly patients who underwent TLDG; POD, postoperative day; TLDG, totally laparoscopic distal gastrectomy; LADG, laparoscopy-assisted distal gastrectomy.

space (21), which may decrease the anesthesia of the upper abdomen; and ii) there may be a different susceptibility to pain and/or analgesic agents between the elderly and non-elderly patients; a negative correlation with age was observed for postoperative pain intensity, as well as analgesic consumption (22-24). Moreover, Sommer et al (25) demonstrated that patients aged $\geq 65$ years experienced less pain compared with patients aged 41-64 years following major surgery.
Jin et al (26) reported that persistent postoperative pain may cause cardiac, respiratory and cerebrovascular complications, resulting in an increase in the risk of an adverse outcome. Adequate postoperative pain management is not only indispensable for patient comfort, but it has also been reported that there is a strong association between effective postoperative pain management and the prevention of postoperative complications $(22,27)$. In this regard, TLDG for gastric cancer in the 

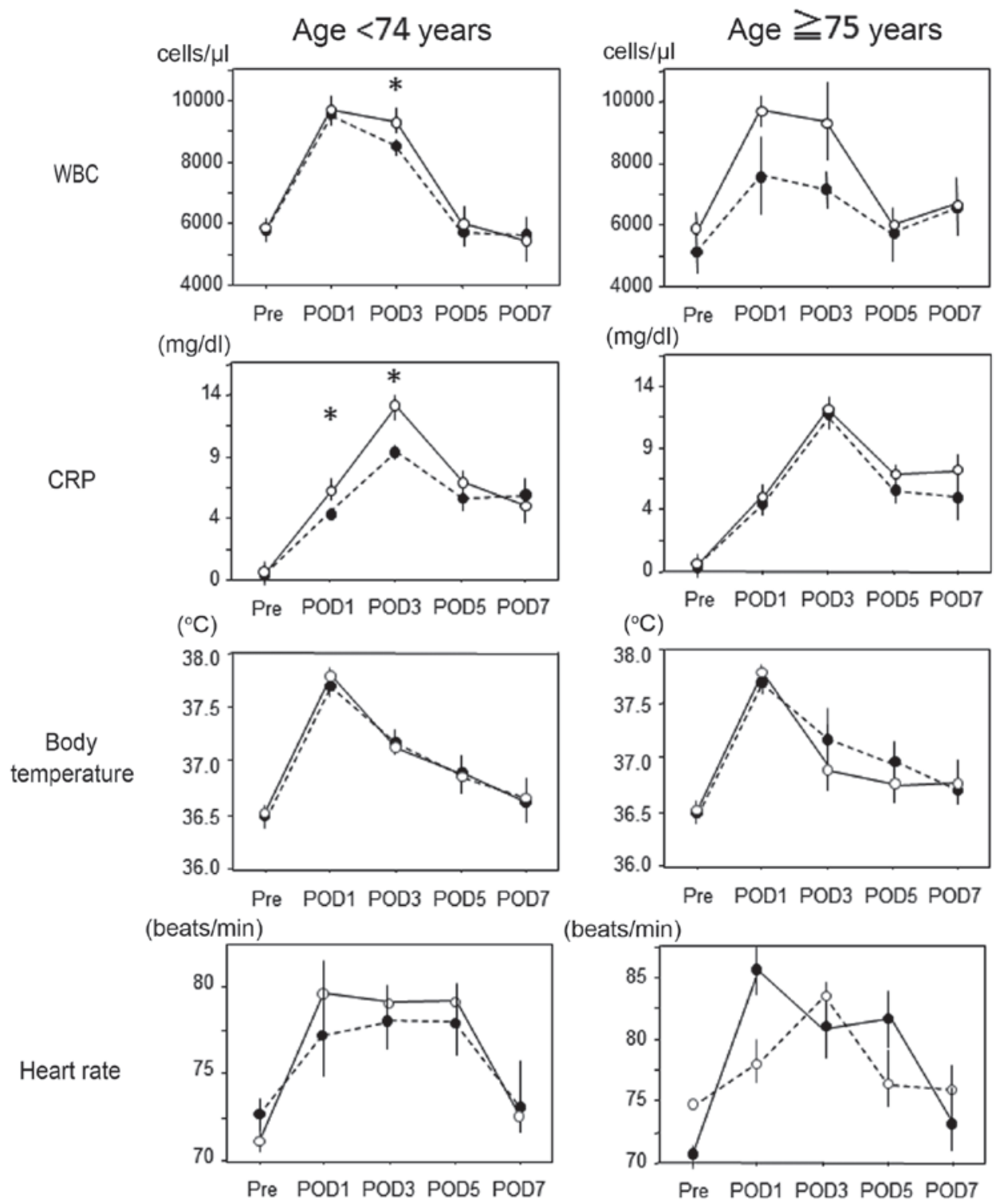

(beats/min)

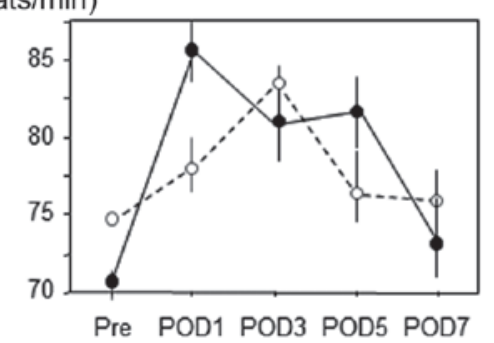

Figure 2. Comparison of postoperative white blood cell count, levels of C-reactive protein, body temperature and heart rate between the TLDG and LADG groups. WBC, white blood cell count; CRP, C-reactive protein; POD, postoperative day; LADG, laparoscopy-assisted distal gastrectomy; TLDG, totally laparoscopic distal gastrectomy. ${ }^{*}<0.05$ for TLDG vs. LADG.

elderly may be the optimal surgical approach in terms of postoperative pain management to improve short-term outcome.

In conclusion, TLDG is suitable for treating elderly patients with gastric cancer, who exhibit the highest mortality rate in the adult surgical population, in terms of postoperative pain.

\section{Acknowledgements}

The authors would like to thank Enago (www.enago.jp) for the English language review.

\section{References}

1. Levi F, Lucchini F, Negri E, Boyle P and La Vecchia C: Changed trends of cancer mortality in the elderly. Ann Oncol 12: 1467-1477, 2001.

2. Kim MG, Kim HS, Kim BS and Kwon SJ: The impact of old age on surgical outcomes of totally laparoscopic gastrectomy for gastric cancer. Surg Endosc 27: 3990-3997, 2013.
3. Creditor MC: Hazards of hospitalization of the elderly. Ann Intern Med 118: 219-223, 1993.

4. Kitano S, Iso $Y$, Moriyama $M$ and Sugimachi K: Laparoscopy-assisted Billroth I gastrectomy. Surg Laparosc Endosc 4: 146-148, 1994.

5. Lu C, Zhou S, Peng Z and Chen L: Quality of D2 lymphadenectomy for advanced gastric cancer: Is laparoscopic-assisted distal gastrectomy as effective as open distal gastrectomy? Surg Endosc 29: 1537-1544, 2015.

6. Kitano S, Shiraishi N, Uyama I, Sugihara K and Tanigawa N; Japanese Laparoscopic Surgery Study Group: A multicenter study on oncologic outcome of laparoscopic gastrectomy for early cancer in Japan. Ann Surg 245: 68-72, 2007.

7. Zeng YK, Yang ZL, Peng JS, Lin HS and Cai L: Laparoscopy-assisted versus open distal gastrectomy for early gastric cancer: Evidence from randomized and nonrandomized clinical trials. Ann Surg 256: 39-52, 2012.

8. Chen XZ, Hu JK, Yang K, Wang L and Lu QC: Short-term evaluation of laparoscopy-assisted distal gastrectomy for predictive early gastric cancer: A meta-analysis of randomized controlled trials. Surg Laparosc Endosc Percutan Tech 19: 277-284, 2009.

9. Cheng Q, Pang TC, Hollands MJ, Richardson AJ, Pleass H, Johnston ES and Lam VW: Systematic review and meta-analysis of laparoscopic versus open distal gastrectomy. J Gastrointest Surg 18: 1087-1099, 2014. 
10. Kim DG, Choi YY, An JY, Kwon IG, Cho I, Kim YM, Bae JM, Song MG and Noh SH: Comparing the short-term outcomes of totally intracorporeal gastroduodenostomy with extracorporeal gastroduodenostomy after laparoscopic distal gastrectomy for gastric cancer: A single surgeon's experience and a rapid systematic review with meta-analysis. Surg Endosc 27: 3153-3161, 2013.

11. Tsujimoto H, Uyama I, Yaguchi Y, Kumano I, Takahata R, Matsumoto Y, Yoshida K, Horiguchi H, Aosasa S, Ono S, et al: Outcome of overlap anastomosis using a linear stapler after laparoscopic total and proximal gastrectomy. Langenbecks Arch Surg 397: 833-840, 2012.

12. Inaba K, Satoh S, Ishida Y, Taniguchi K, Isogaki J, Kanaya S and Uyama I: Overlap method: Novel intracorporeal esophagojejunostomy after laparoscopic total gastrectomy. J Am Coll Surg 211: e25-e29, 2010.

13. Kanaya S, Kawamura Y, Kawada H, Iwasaki H, Gomi T, Satoh S and Uyama I: The delta-shaped anastomosis in laparoscopic distal gastrectomy: Analysis of the initial 100 consecutive procedures of intracorporeal gastroduodenostomy. Gastric Cancer 14 365-371, 2011.

14. Ikeda O, Sakaguchi Y, Aoki Y, Harimoto N, Taomoto J, Masuda T, Ohga T, Adachi E, Toh Y, Okamura T, et al: Advantages of totally laparoscopic distal gastrectomy over laparoscopically assisted distal gastrectomy for gastric cancer. Surg Endosc 23: 2374-2379, 2009.

15. Japanese Gastric Cancer Association: Japanese classification of gastric carcinoma: 3rd English edition. Gastric Cancer 14: 101-112, 2011.

16. Omori T, Oyama T, Akamatsu H, Tori M, Ueshima S, Nakahara M and Toshirou N: A simple and safe method for gastrojejunostomy in laparoscopic distal gastrectomy using the hemidouble-stapling technique: Efficient purse-string stapling technique. Dig Surg 26 : 441-445, 2009.
17. Jones AG and Hunter JM: Anaesthesia in the elderly. Special considerations. Drugs Aging 9: 319-331, 1996.

18. Takeshita H, Ichikawa D, Komatsu S, Kubota T, Okamoto K, Shiozaki A, Fujiwara H and Otsuji E: Surgical outcomes of gastrectomy for elderly patients with gastric cancer. World J Surg 37: 2891-2898, 2013.

19. Fujiwara S, Noguchi T, Harada K, Noguchi T, Wada S and Moriyama H: How should we treat gastric cancer in the very elderly? Hepatogastroenterology 59: 620-622, 2012.

20. Dittmar Y, Rauchfuss F, Götz M, Scheuerlein H, Jandt K and Settmacher U: Impact of clinical and pathohistological characteristics on the incidence of recurrence and survival in elderly patients with gastric cancer. World J Surg 36: 338-345, 2012.

21. Sharrock NE: Epidural anesthetic dose responses in patients 20 to 80 years old. Anesthesiology 49: 425-428, 1978.

22. Gagliese L and Katz J: Age differences in postoperative pain are scale dependent: A comparison of measures of pain intensity and quality in younger and older surgical patients. Pain 103: 11-20, 2003.

23. Ip HY, Abrishami A, Peng PW, Wong J and Chung F: Predictors of postoperative pain and analgesic consumption: A qualitative systematic review. Anesthesiology 111: 657-677, 2009.

24. Shafer SL: The pharmacology of anesthetic drugs in elderly patients. Anesthesiol Clin North America 18: 1-29, 2000.

25. Sommer M, de Rijke JM, van Kleef M, Kessels AG, Peters ML, Geurts JW, Patijn J, Gramke HF and Marcus MA: Predictors of acute postoperative pain after elective surgery. Clin J Pain 26: 87-94, 2010.

26. Jin F and Chung F: Minimizing perioperative adverse events in the elderly. Br J Anaesth 87: 608-624, 2001.

27. Joshi GP and Ogunnaike BO: Consequences of inadequate postoperative pain relief and chronic persistent postoperative pain. Anesthesiol Clin North America 23: 21-36, 2005. 